\title{
Results of the Bethesda System in Patients Undergoing Thyroidectomy-A Single-Center Experience
}

\author{
(1) Sönmez Ocak, (1) Ömer Faruk Bük, (1) Kürşat Yemez \\ University of Health Sciences, Samsun Training and Research Hospital, Department of General Surgery, Samsun, Turkey
}

\section{Abstract}

Objective: To compare preoperative fine needle aspiration biopsy (FNAB) and postoperative histopathological findings in patients undergoing thyroidectomy and to validate the Bethesda System for Reporting Thyroid Cytopathology (TBSRTC).

Methods: Data from 366 patients who underwent thyroidectomy between 2014-2016 were analyzed retrospectively and the variables related to thyroid cancer were investigated.

Results: Of 366 patients, 44 (12\%) were male and 322 (88\%) were female. Regarding FNAB results according to TBSRTC, 23 (6.3\%) patients had category I, 79 (21.6\%) had category II, 128 (35\%) had category III, 113 (30.9\%) had category IV, nine (3.8\%) patients had category V and 14 (2.5\%) had category VI cytology. Histopathological examination revealed thyroid cancer in 65 (17.7\%) patients. The Bethesda System was found to have a sensitivity of $73.9 \%$ and a specificity of $96 \%$. There was no association between thyroid cancer and other variables except male gender.

Conclusion: Although TBSRTC has an acceptable sensitivity and specificity, the risk of malignancy in category III and IV patients may vary. Therefore, multidisciplinary approach should be considered during treatment planning and surgical treatment option should be kept in mind.

Keywords: Fine needle aspiration biopsy, Bethesda System, thyroid nodule, thyroid cancer, thyroidectomy

\section{INTRODUCTION}

The incidence of thyroid nodules increased to 50\%-70\% with the use of high-resolution ultrasonography (US) (1). The incidence of cancer in thyroid nodules varies between 2\% and 15\% (2). Fine needle aspiration biopsy (FNAB) has an important role in the evaluation of thyroid nodules and the detection of cancer risk. Early diagnosis of clinically insignificant thyroid cancers is possible with FNAB, and patients are protected from unnecessary surgery and associated complications (3). With the widespread use of FNAB, conflicting reports between pathologists have started to emerge in the evaluation of cytology. The Bethesda System for Reporting Thyroid Cytopathology (TBSRTC) was developed in 2007 to eliminate terminological confusion. According to TBSRTC, FNAB results are divided into six categories: non-diagnostic, benign, atypia of undetermined significance/ follicular lesion of undetermined significance, follicular nodule/ suspicious follicular nodule, suspicious for malignancy and malignant (Table 1) (4).

Central and Eastern Black Sea region are endemic regions for thyroid nodules. The aim of this retrospective analysis was to validate TBSRTC by comparing FNAB and histopathological (HP) results of 366 patients who underwent total thyroidectomy in Samsun Training and Research Hospital General Surgery Clinic between 2014-2016.

\section{METHODS}

The demographic characteristics of the patients, FNAB results according to TBSRTC, characteristics of single nodule or multinodular goiter, nodule diameters and HP results were recorded. All biopsies were taken under the guidance of an 
US by a radiologist with a 22 gauge needle and 10 cc injector in outpatient clinic settings. TBS was used for cytological classification. Repeat FNAB was planned for patients who had a non-diagnostic FNAB cytology. Follow-up or surgical treatment was suggested to patients with a second non-diagnostic FNAB cytology. Patients with nodule growth or suspicious US findings (solid hypoechoic nodules or cystic, microcalcified nodule with extra-thyroidal extension and irregular margins) during the follow-up period and patients who accepted surgery instead of follow-up were included in the study. Thyroidectomy was performed due to various indications other than cancer (cosmetic causes, trachea compression, hyperthyroidism) in patients with benign cytology. The HP findings of the patients were compared with the preoperative cytology results. Incidence of malignancy, suspected malignancy with benign cytology in TBSRTC, sensitivity and specificity of malignant cytology category, and the positive predictive and negative predictive values (PPD and NPD) were calculated in groups divided according to TBSRTC. In addition, the presence of a significant relationship between cancer incidence and age, gender, single nodule/multinodularity and nodule diameter parameters was investigated.

\section{Statistical Analysis}

SPSS 23.0 (IBM Corparation, Armonk, New York, United States) program was used for statistical analysis. While mean, standard error and minimum-maximum values were used for quantitative variables, categorical variables were expressed as n (\%). Independent samples-t test was used for comparing the quantitative data of the two groups and chi-square test was used to compare the categorical data. $\mathrm{P}<0.05$ was considered statistically significant.

\section{RESULTS}

The mean age of the patients was 50.47 (18-79) years. Fortyfour (12\%) patients were male (88\%) and 322 were female. The median nodule diameter was calculated as $21.44 \mathrm{~mm}$ (4-65). A single nodule was detected in US in 152 (41.5\%) patients, while the remaining 214 (58.5\%) patients had multinodular goiter (Table 2). According to TBSRTC, 23 (6.3\%) patients had category I, 79 (21.6\%) had category II, 128 (35\%) had category III, 113 (\%30.9) had category IV, nine (3.8\%) patients had category V and 14 (2.5\%) had category VI cytology (Figure 1). HP examination revealed thyroid cancer in 65 (17.7\%) patients. Papillary microcarcinoma was detected in 30 of 65 patients (8.2\%) and papillary carcinoma in 34 patients (9.3\%). Medullary thyroid cancer was seen in one (0.3\%) patient. Of the remaining 301 patients, 290 (79.2\%) had benign nodules, six (1.6\%) had follicular adenoma and five (1.4\%) had Hurthle cell adenoma. Table 3 shows the HP results of the patients divided into six categories according to TBSRTC after thyroidectomy. Thyroid cancer was found in six of 79 patients with benign cytology. Considering category II, V and VI, TBSRTC was found to have a sensitivity of $73.9 \%$ and a specificity of $96 \%$. In addition, PPD was calculated as $73.9 \%$, NPD was $92.4 \%$ and accuracy was $88.2 \%$. The incidence of cancer was found to be higher in men compared to women ( $31.8 \%$ vs. $18.8 \%, p=0.009)$.

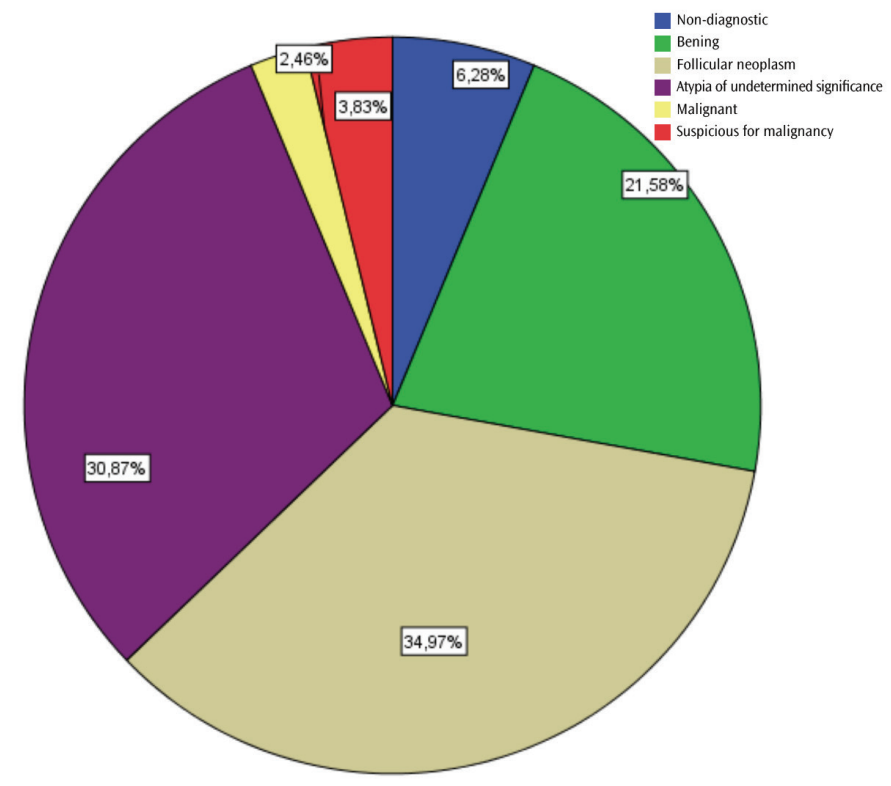

Figure 1. Distribution of FNAB results according to Bethesda criteria FNAB: Fine needle aspiration biopsy

\begin{tabular}{|l|l|l|}
\hline \multicolumn{2}{|l|}{ Table 1. The Bethesda System } \\
\hline Diagnostic category & $\begin{array}{l}\text { Risk of } \\
\text { malignancy (\%) }\end{array}$ & Treatment recommendation \\
\hline Non-diagnostic or unsatisfactory & $1-4$ & Repeat fine needle aspiration biopsy \\
\hline Benign & $0-3$ & Follow-up \\
\hline Atypia of undetermined significance/follicular lesion of undetermined significance & $\sim 5-15$ & Repeat fine needle aspiration biopsy \\
\hline Follicular neoplasm & $15-30$ & Lobectomy \\
\hline Suspicious for malignancy & $60-75$ & Lobectomy/near-total thyroidectomy \\
\hline Malignant & $97-99$ & Near-total thyroidectomy \\
\hline
\end{tabular}


There was no statistically significant difference between benign and malign HP groups in terms of nodule diameter, single nodule or multinodular goitre on US findings and age $(p=0.097$,

\begin{tabular}{|l|l|}
\hline \multicolumn{2}{|l|}{$\begin{array}{l}\text { Table 2. Distribution of patients according to age, gender, } \\
\text { nodule diameter and ultrasonography results }\end{array}$} \\
\hline Age: mean (min-max, SD) & $50.47(18-79,13.073)$ \\
\hline Gender & $44(12 \%)$ \\
Male (\%) & $322(88 \%)$ \\
Female (\%) & $21.44(4-65,10.864)$ \\
\hline Nodule diameter (mm): & \\
Mean (min-max, SD) & $152(41.5 \%)$ \\
\hline Ultrasonography & $214(58.5 \%)$ \\
One nodule (\%) & \\
Multinodular (\%) &
\end{tabular}

$p=0.267, p=0.863$, respectively) (Table 4). According to FNAB results, when the patients in category III and IV were evaluated separately, male gender was found to be a risk factor for thyroid cancer in the category III group $(p=0.015)$; no relationship was found between thyroid cancer and age, gender, nodule diameter and nodular/multinodular goiter in the category IV (Table 5).

\section{DISCUSSION}

In the last half century, as in all over the world, the incidence of thyroid cancer increases and mortality due to thyroid cancer decreases. The most important reason for the increase in the incidence of thyroid cancer is the development of diagnostic methods (5). Nowadays, the FNAB is widely used as the first-line diagnostic method in the management of thyroid

\begin{tabular}{|c|c|c|c|c|c|c|c|c|}
\hline \multirow[b]{2}{*}{$\begin{array}{l}\text { Bethesda } \\
\text { category }\end{array}$} & \multicolumn{7}{|c|}{ Histopathological results } & \multirow[b]{2}{*}{$\begin{array}{l}\text { Risk of } \\
\text { malignancy (\% }\end{array}$} \\
\hline & B & FA & HCA & PMC & PC & MTC & Total & \\
\hline 1 & 16 & 3 & 2 & 0 & 2 & 0 & 23 & 8 \\
\hline II & 72 & 0 & 1 & 3 & 2 & 1 & 79 & 7.6 \\
\hline III & 99 & 1 & 2 & 13 & 13 & 0 & 128 & 20.3 \\
\hline IV & 97 & 2 & 0 & 9 & 5 & 0 & 113 & 12.3 \\
\hline V & 3 & 0 & 0 & 2 & 4 & 0 & 9 & 66.6 \\
\hline VI & 3 & 0 & 0 & 3 & 8 & 0 & 14 & 78.5 \\
\hline
\end{tabular}

\begin{tabular}{|c|c|c|c|}
\hline & Benign & Malign & $\mathrm{p}$ \\
\hline Age (mean, SD) & $50.52(13.025)$ & $50.22(13.389)$ & 0.916 \\
\hline NG/MNG (\%) & $121 / 180(33 / 49)$ & $31 / 34(8.4 / 9.2)$ & 0.266 \\
\hline
\end{tabular}

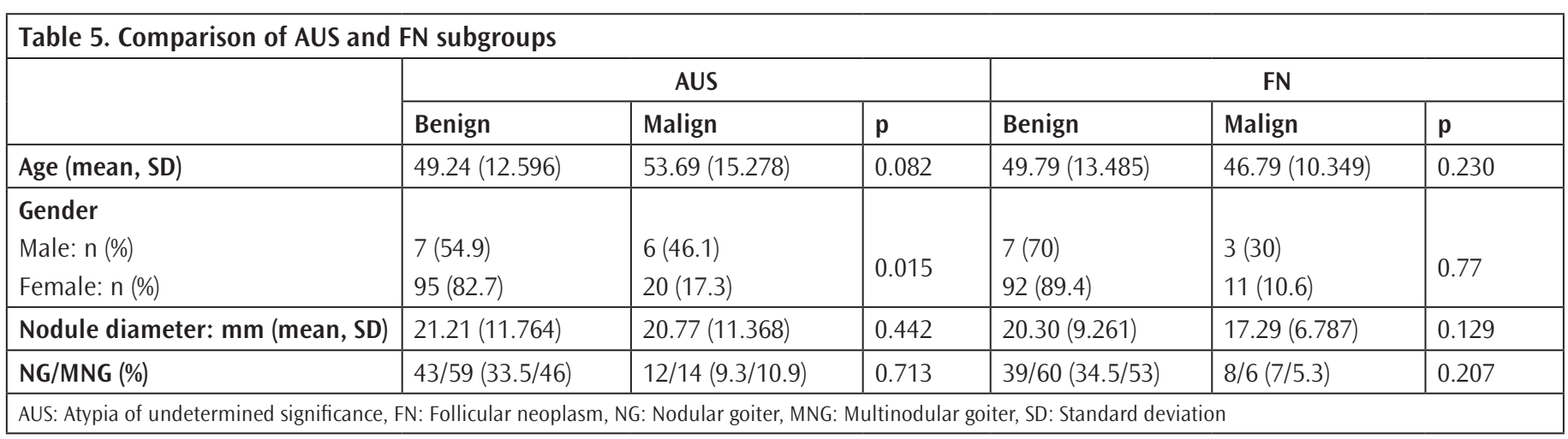


nodules according to US findings. The incidence of cancer after thyroidectomy has increased from $10-20 \%$ to $50 \%$. Thanks to the FNAB, unnecessary surgeries and associated complications and cost decreased significantly (6). The widespread use of FNAB has brought along the need for standardization in the reporting of cytology results, for this purpose, TBSRTC was developed in 2007 and the cytology results were divided into six categories.

In order to accept the FNAB material sufficient for diagnosis, the material should consist of minimum 5-6 separate groups consisting of at least 10 follicular epithelial cells (4). In studies conducted, $89-95 \%$ of FNAB samples from thyroid nodules were reported to be sufficient for diagnosis. While $55-74 \%$ of the cytology examinations are reported as category I, category IV and $V$ vary between 2-5\% (7-10). Similar data were obtained in our study. In our series, $93.7 \%$ of the samples were sufficient for diagnosis and the rate of category IV-V was $6.2 \%$. However, unlike other studies, category II rate was $21.5 \%$ in our study. The reason for this difference is the exclusion of category II patients who were not indicated for surgical treatment and inclusion of patients who underwent thyroidectomy only. The prevalence of cancer in category II cytology varies between $1-3.2 \%$ in large case series and meta-analyzes (11-16). In our study, preoperative cytology of 79 patients was reported as category II and six patients (6.32\%) had thyroid cancer. In this group, cancer was detected in only one of 32 patients with single nodule and in five of 47 patients with multiple nodules. The cytological examination of the patients with multinodular goiter is taken from the dominant nodule and cancer is observed in non-dominant nodules in these patients. It is natural that the incompatibility with the literature is due to this reason. Regarding 32 patients with single nodules, the incidence of cancer is 3.1\%, which is parallel to the literature.

The incidence of cancer in category 5 and category 6 cytology varies between $60-75 \%$ and $97-99 \%$, respectively, in the original article in which TBSRTC was defined and in subsequent metaanalysis with a considerable number of cases $(4,8,17)$. In our study, these rates were determined as $66.6 \%$ and $78.5 \%$, respectively. In our cases, the incidence of cancer, especially in category VI cytology, is low compared to the literature. There may be two reasons for this difference: the experience of the pathologist in TBSRTC and the low number of cases. However, considering the accuracy of $88.6 \%$ when the categories II, V and VI are considered together, we believe that TBSRTC can be used safely in these categories. In the light of the information obtained from the guidelines, the general approach in category II cases is follow-up and surgical treatment in the presence of indications for surgery other than cancer. In contrast, the approach is surgical treatment in category $\mathrm{V}$ and VI. The main problem in clinical practice is category III and IV cases.

The definition "atypia of undetermined significance/follicular lesion of undetermined significance" is used for cytology specimens consisting of cells with unexpected structural and nuclear atypia in benign changes and with no risk other than that (18). This cytological description constitutes $1-27 \%$ of FNAB results (19). The cancer risk in Bethesda category III is reported to be between $5 \%$ and $15 \%$, although many studies have reported that cancer rates vary between $17-39 \%$ (4, 2027). In our study, the incidence of thyroid cancer was $20.3 \%$ in patients with category III cytology. In the American Thyroid Association guideline, considering the suspected clinical and sonographic characteristics, category III patients are advised to undergo repeat biopsy or molecular study instead of follow-up or diagnostic surgery (28).

In some studies, it has been suggested that core biopsy is more useful and tolerable than FNAB $(29,30)$. However, the American Association of Clinical Endocrinologists, the Italian Association of Clinical Endocrinologists and European Thyroid Association joint guideline concludes that core biopsy does not provide additional benefit but increases morbidity. Again in this guide, it is emphasized that malignancy criteria (head and neck radiation history, family history, <14->70 years, male gender, fixed nodule, fast growing nodule, etc.) have low predictive value and that there is yet not enough data to suggest that US elastography can be used routinely. In addition, it was emphasized that surgery should be considered primarily in these cases, considering that molecular tests are expensive and can be performed in only private centers (31). It has also been shown that some of the patients that underwent repeat FNAB and interpreted as benign had malignancy after resection (32). In these patients, it would be most appropriate to plan the treatment by a multidisciplinary council with a surgeon, medical endocrinologist, radiologist and cytopathologist with considering the opinion of the patients. Another category "follicular nodule/suspicious follicular nodule" constitute approximately $10-25 \%$ of all FNABs. In various studies, malignancy rates in category IV cases have been reported between 18-28\% (9, 33-35). In our study, the rate of malignancy was lower than expected (12.3\%).

In general, there are some differences between TBSRTC and our results. Among the reasons for these differences, the experience of the cytopathologist, FNAB method and the endemic nature of our region can be considered. When risk factor analysis 
was performed, only male gender was found to be significant and other parameters were statistically insignificant. For the validation of TBSRTC, cohort studies with larger cases are needed in our region.

\section{CONCLUSION}

Thyroid FNAB has an important role in the management of thyroid nodules. Although TBSRTC is guiding, it may be incompatible with published studies. This difference is directly related to the experience of the pathologist, the method of FNAB and even the resources of the healthcare center. In conclusion, the clinician should act with other departments in the management of a thyroid nodule and should be in a patientoriented multidisciplinary approach.

\section{Ethics}

Ethics Committee Approval: Retrospective study.

Informed Consent: Retrospective study.

Peer-review: External and internal peer-reviewed.

\section{Authorship Contributions}

Surgical and Medical Practices: S.O., Ö.B., K.Y., Concept: S.O., Ö.B., Design: S.O., K.Y., Data Collection or Processing: S.O., Ö.B., K.Y., Analysis or Interpretation: S.O., K.Y., Literature Search: S.O., Ö.B., K.Y., Writing: S.O., Ö.B.

Conflict of Interest: No conflict of interest was declared by the authors.

Financial Disclosure: The authors declared that this study received no financial support.

\section{REFERENCES}

1. Guth S, Theune U, Aberle J, Galach A, Bamberger CM. Very high prevalence of thyroid nodules detected by high frequency $(13 \mathrm{MHz})$ ultrasound examination. Eur J Clin Invest 2009;39:699-706.

2. Kim YY, Han K, Kim EK, Moon HJ, Yoon JH, Park VY, et al. Validation of the 2015 American thyroid association management guidelines for thyroid nodules with benign cytologic findings in the era of the Bethesda system. AJR Am J Roentgenol 2018:210:629-34.

3. Polyzos SA, Kita M, Avramidis A. Thyroid Stepwise diagnosis and management. Hormones 2007;6:101-19.

4. Cibas ES, Ali SZ. The Bethesda system for reporting thyroid cytopathology. Am J Clin Pathol 2009;132:658-65.

5. La Vecchia C, Malvezzi M, Bosetti C, Garavello W, Bertuccio P, Levi F, et al. Thyroid cancer mortality and incidence: a global overview. Int J Cancer 2015;136:2187-95.

6. Yassa L, Cibas ES, Benson CB, Frates MC, Doubilet PM, Gawande AA, et al. Long-term assessment of a multidisciplinary approach to thyroid nodule diagnostic evaluation. Cancer 2007;111:508-16.
7. Theoharis CG, Schofield KM, Hammers L, Udelsman R, Chhieng DC. The Bethesda thyroid fine-needle aspiration classification system: year 1 at an academic institution. Thyroid 2009;19:1215-23.

8. Luu MH, Fischer AH, Pisharodi L, Owens CL. Improved preoperative definitive diagnosis of papillary thyroid carcinoma in FNAs prepared with both ThinPrep and conventional smears compared with FNAs prepared with ThinPrep alone. Cancer Cytopathol 2009;119:68-73.

9. Bongiovanni M, Spitale A, Faquin WC, Mazzucchelli L, Baloch ZW. The Bethesda system for reporting thyroid cytopathology: a meta-analysis. Acta Cytol 2012;56:333-9.

10. Nayar R, Ivanovic M.The indeterminate thyroid fine-needle aspiration: experience from an academic center using terminology similar to that proposed in the 2007 National Cancer Institute Thyroid Fine Needle Aspiration State of the Science Conference. Cancer 2009;117:195-202.

11. Chehade JM, Silverberg AB, Kim J, Case C, Mooradian A. Role of repeated fine-needle aspiration of thyroid nodules with benign cytologic features. Endocr Pract 2001;7:237-43.

12. Orlandi A, Puscar A, Capriata E, Fideleff H. Repeated fine-needle aspiration of the thyroid in benign nodular thyroid disease: critical evaluation of longterm follow-up. Thyroid 2005;15:274-8.

13. Oertel YC, Miyahara-Felipe L, Mendoza MG, Yu K. Value of repeated fine needle aspirations of the thyroid: an analysis of over ten thousand FNAs. Thyroid 2007;17:1061-6.

14. Erdogan MF, Kamel N, Aras D, Akdogan A, Baskal N, Erdogan G. Value of re-aspirations in benign nodular thyroid disease. Thyroid 1998;8:108790.

15. Illouz F, Rodien P, Saint-Andre JP, Triau S, Laboureau-Soares S, Dubois $S$, et al. Usefulness of repeated fine-needle cytology in the follow-up of nonoperated thyroid nodules. Eur J Endocrinol 2007;156:303-8.

16. Tee YY, Lowe AJ, Brand CA, Judson RT. Fineneedle aspiration may miss a third of all malignancy in palpable thyroid nodules: a comprehensive literature review. Ann Surg 2007;246:714-20.

17. Jo VY, Stelow EB, Dustin SM, Hanley KZ. Malignancy risk for fneneedle aspiration of thyroid lesions according to The Bethesda System for Reporting Thyroid Cytopathology. Am J Clin Pathol 2010;134:450-6.

18. Krane JF, Nayar R, Renshaw AA. Atypia of undetermined significance/ follicular lesion of undetermined significance. In: Ali SZ, Cibas ES (eds) The Bethesda System for Reporting Thyroid Cytopathology. 2010; Springer, pp 37-49.

19. Ohori NP, Schoedel KE. Variability in the atypia of undetermined significance/ follicular lesion of undetermined significance diagnosis in the Bethesda System for Reporting Thyroid Cytopathology: sources and recommendations. Acta Cytol 2011;55:492-8.

20. Mathur A, Najafian A, Schneider EB, Zeiger MA, Olson MT. Malignancy risk and reproducibility associated with atypia of undetermined significance on thyroid cytology. Surgery 2014;156:1471-6.

21. Choi YJ, Baek JH, Ha EJ, Lim HK, Lee JH, Kim JK, et al. Different risk of malignancy and management recommendations in subcategories of thyroid nodules with atypia of undetermined significance (AUS) or follicular lesion of undetermined significance (FLUS): The role of US-guided core-needle biopsy (CNB). Thyroid 2014;24:494-501.

22. Lee YS, Kim HK, Chang H, Kim SM, Kim BW, Chang HS, et al. Diagnostic thyroidectomy may be preferable in patients with suspicious ultrasonography features after cytopathology diagnosis of AUS/FLUS in the Bethesda system. Medicine (Baltimore) 2015;94:e2183.

23. Broome JT, Carmen CC. The impact of atypia/follicular lesion of undetermined significance on the rate of malignancy in thyroid fine- 
needle aspiration: evaluation of the Bethesda System for Reporting Thyroid Cytopathology. Surgery 2011;150:1234-41.

24. Dincer N, Balci S, Yazgan A, Guney G, Ersoy R, Cakir B, et al. Follow-up of atypia and follicular lesions of undetermined significance in thyroid fine needle aspiration cytology. Cytopatholog 2013;24:385-90.

25. Garg S, Naik LP, Kothari KS, Fernandes GC, Agnihotri MA, Gokhale JC. Evaluation of thyroid nodules classified as Bethesda category III on FNAC. I Cytol 2017;34:5-9.

26. Ho AS, Sarti EE, Jain KS, Wang H, Nixon IJ, Shaha AR, et al. Malignancy rate in thyroid nodules classified as Bethesda category III (AUS/FLUS). Thyroid 2014;24:832-9.

27. Kayilioglu SI, Dinc T, Sozen I, Senol K, Katar K, Karabeyoglu M, et al. Thyroid nodules with atypia or follicular lesions of undetermined significance (AUS/ FLUS): Analysis of variables associated with outcome. Asian Pac J Cancer Prev 2014;15:10307-11.

28. Haugen BR, Alexander EK, Bible KC, Doherty GM, Mandel SJ, Nikiforov YE, et al. American Thyroid Association management guidelines for adult patients with thyroid nodules and differentiated thyroid cancer: the American Thyroid Association guidelines task force on thyroid nodules and differentiated thyroid cancer. Thyroid 2016;26:1-133.

29. Na DG, Kim JH, Sung JY, Baek JH, Jung KC, Lee H, et al. Core-needle biopsy is more useful than repeat fine-needle aspiration in thyroid nodules read as nondiagnostic or atypia of undetermined significance by the Bethesda system for reporting thyroid cytopathology. Thyroid 2012;22:468-75.

30. Nasrollah N, Trimboli P, Rossi F, Amendola S, Guidobaldi L, Ventura C, et al. Patient's comfort with and tolerability of thyroid core needle biopsy. Endocrine 2014;45:79-83.

31. Gharib H, Papini E, Paschke R, Duick D, Valcavi R, Hegedüs L, et al. American Association of Clinical Endocrinologists, Associazione Medici Endocrinologi, and European Thyroid Association medical guidelines for clinical practice for the diagnosis and management of thyroid nodules. Endocrine Practice 2010;16(Suppl 1):1-43.

32. Vanderlaan PA, Marqusee E, Krane JF. Clinical outcome for atypia of undetermined significance in thyroid fine-needle aspirations: should repeated fna be the preferred initial approach? Am J Clin Pathol 2011;135:770-5.

33. Najafian A, Olson MT, Schneider EB, Zeiger MA. Clinical presentation of patients with a thyroid follicular neoplasm: are there preoperative predictors of malignancy?. Ann Surg Oncol 2015;22:3007-13.

34. Yoon RG, Baek JH, Lee JH, Choi YJ, Hong MJ, Song DE, et al. Diagnosis of thyroid follicular neoplasm: fine-needle aspiration versus core-needle biopsy. Thyroid 2014;24:1612-7.

35. Keskek M, Ocak S, Ozalp N, Koc M, Tez M. Clinical significance of Hürthle cells in fine needle aspiration biopsy for multinodular goitre. Endocr Regul 2010;44:65-8. 